\title{
CREhAR en la era digital. La primera cátedra UNESCO en el campo emergente del patrimonio contemporáneo
}

\begin{abstract}
Residenciada en la Universidad de Sevilla y vinculada a su Escuela de Arquitectura, CREhAR (Creative Research and Education in heritage Assessment and Regeneration) in the Digital Era es la primera cátedra UNESCO del mundo especializada en patrimonio contemporáneo. CREhAR dinamiza una red internacional, de la que forman parte universidades, instituciones públicas, empresas, asociaciones y otras cátedras, preocupada por la identificación, valoración y conservación del más modesto e invisibilizado patrimonio construido, que ha sido señalado por la UNESCO como un espacio de oportunidad.
\end{abstract}

Mar Loren-Méndez | Directora de la Cátedra UNESCO CREhAR, Universidad de Sevilla

URL de la contribución <http://www.iaph.es/revistaph/index.php/revistaph/article/view/5010>

CREhAR. En la frontera de los estudios patrimoniales Las cátedras UNESCO se erigen como centros de reflexión y centros de acción. En concreto, afrontan la responsabilidad de trabajar en los nuevos desafíos de la sociedad, para contribuir a su desarrollo y resiliencia y evitar las contradicciones implícitas en el concepto de desarrollo sostenible. En última instancia aspiran a convertirse en polos de excelencia y de innovación en campos de emergencia. Para afrontarlos deben actuar como puentes entre la academia, las instituciones y la comunidad, por lo que cada cátedra UNESCO está a cargo de construir redes internacionales que, lejos de la introspección académica o institucional, aseguren la participación activa de la comunidad. Por tanto, la cooperación a nivel mundial fundamentada en lo social está en la base de la dinámica y en la misma esencia de las cátedras. Todo ello las convierte en espacios idóneos para trabajar de manera activa y transversal en el campo del patrimonio cultural y contribuir a los pilares de la sostenibilidad-económico, social, ambiental-, con un énfasis integrador fundamental en la cultura como cuarto pilar.

\section{La urgencia como oportunidad. Nuestro quehacer en el patrimonio arquitectónico contemporáneo}

En 2019, la Unesco aprueba establecer en Andalucía la cátedra Unesco Built Urban Heritage in the Digital Era, CREhAR (Creative Research and Education on heritage Assessment and Regeneration). Esta se centra en la identificación, valorización y conservación de la parte más invisibilizada e incluso denostada del patrimonio construido: arquitecturas sin autoría reconocida, sin programas representativos y localizadas en territorios considerados periféricos. La preocupación por este patrimonio no excepcional -de ahí la h minúscula de sus siglas- se presenta como tarea urgente y también como un fascinante desafío para la cátedra CREhAR.

El patrimonio contemporáneo se trata del más numeroso de entre los denominados "no excepcionales" (European Commission 2004; UNESCO 2012): en efecto, a pesar de que la humanidad ha construido más en estos últimos 200 años que en el resto de su larga historia, este patrimonio construido, componente integral de nuestro entorno, es poco conocido y valorado por la ciudadanía y el menos apreciado y protegido por las instituciones, lo que le hace sumamente vulnerable y en peligro de desaparecer. Aunque somos testigos de una labor creciente de reconocimiento singularizado en patrimonios contemporáneos como el industrial, el patrimonio residencial, los cementerios o incluso las infraestructuras, entre otros, queda una labor ingente por hacer en este campo.

Esta escasa presencia de nuestro patrimonio del siglo XIX y XX no ha pasado inadvertido a la Unesco. En 2003, en el contexto del Modern Heritage Program, instó a una actitud proactiva en pro de aquellos patrimonios menos representados en la Lista de Patrimonio Mundial, poniendo como ejemplo significativo el patrimonio con- 


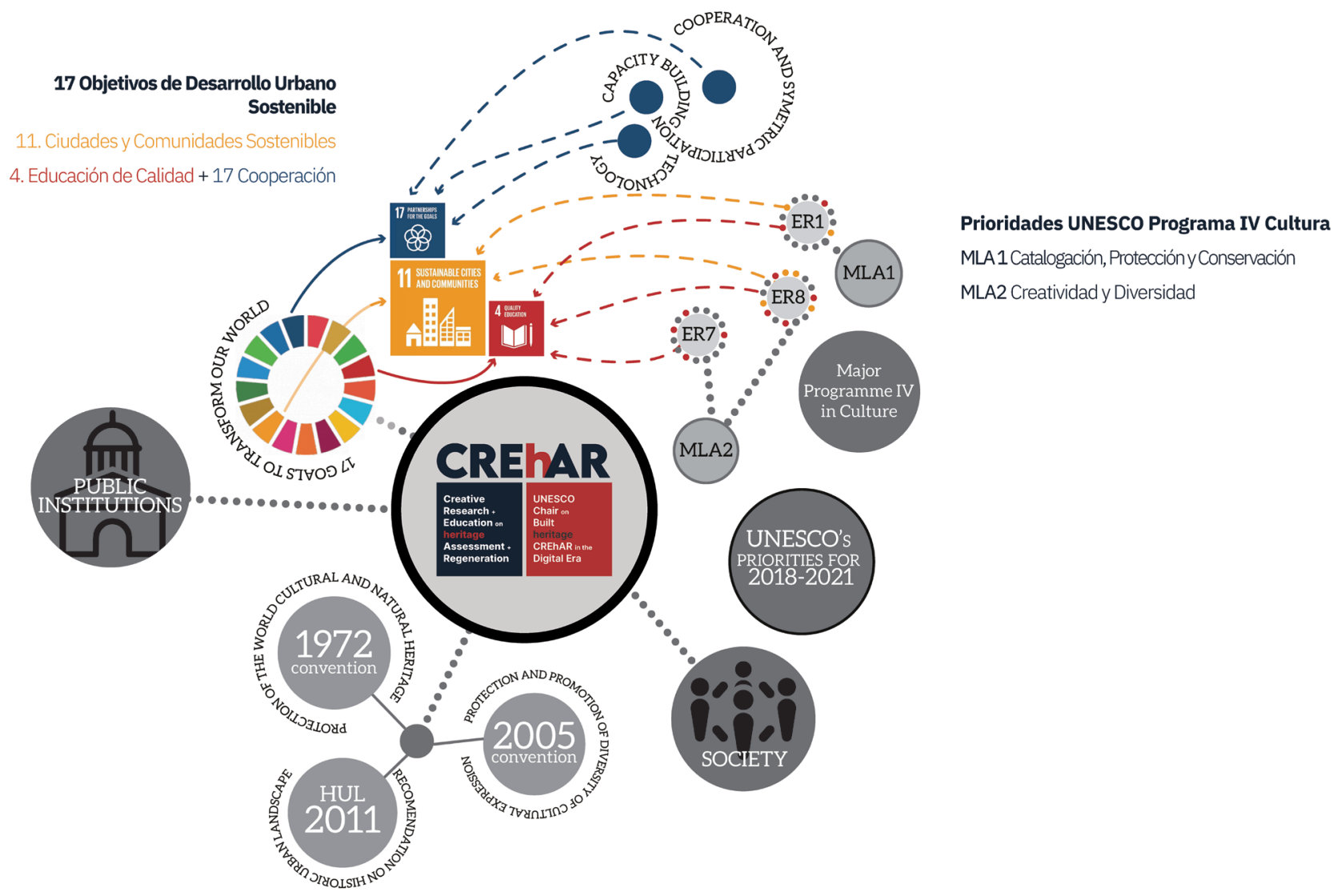

Diagrama de la cátedra Unesco CREhAR en el marco de los programas, convenciones y recomendaciones de la Unesco y de los ODS de la ONU | conceptualización Mar Loren-Méndez; diseño gráfico Pedro García Agenjo

temporáneo. En 2017 Unesco fue más allá y lo consideró campo de auténtica oportunidad investigadora y económica ante la lentitud de su incorporación a la Lista de Patrimonio.

Tras este esfuerzo de equilibrio, de conservar nuestro patrimonio menos representado, subyace una idea: el patrimonio de nuestro entorno construido se aleja ya del monumento y es la diversidad cultural lo que se identifica como principal valor de nuestro patrimonio arquitectónico, urbano y territorial.

Una red actualizada y en igualdad. La cooperación para la salvaguarda de la diversidad cultural

El patrimonio se aborda en CREhAR desde el diálogo en los diferentes países, clave para identificar la singularidad patrimonial y, consecuentemente, asegurar la pro- tección internacional de la diversidad cultural, promover el respeto por todas las culturas y, en última instancia, contribuir a la paz mundial. La aproximación a este patrimonio diverso se efectúa desde la cooperación internacional: la cátedra promueve la simetría en el proceso de cooperación, por lo que evita jerarquías de centro y periferia en el diálogo intercultural, en la línea de lo que recoge la Carta de Cracovia. La cátedra CREhAR contribuye así al enriquecimiento de las relaciones humanas, a una celebración comunitaria de un patrimonio compartido.

En esa diversidad cultural, la participación en igualdad de mujeres y hombres en el campo concreto del patrimonio contemporáneo asegura, sin duda, una mayor riqueza e integridad en los procesos patrimoniales. De esta forma, se contribuye no solo al logro de aspiraciones colectivas, 
sino a dar soporte a objetivos individuales, tanto en formación, como en investigación y docencia.

La aproximación al patrimonio debe caracterizarse indefectiblemente por la constante actualización de los estudios patrimoniales. CREhAR se compromete con la difícil, y a veces imposible tarea, de la actualidad patrimonial desde la condición multiescalar del patrimonio, la interdisciplinariedad para abordar la complejidad patrimonial y la importancia del patrimonio intangible.

Se alinea así con las distintas declaraciones y prioridades de los programas Unesco, en la línea innovadora de cultura y patrimonio como vector fundamental de los ODS.

\section{Patrimonio, creatividad y nuevas tecnologías. Creación en el campo metodológico}

La cátedra CREhAR se posiciona de manera decidida en el uso de la tecnología desde la participación y la transferencia global del conocimiento, en la relación no solo instrumental sino conceptual con el patrimonio. Las TIC se incorporan así no como una moda o requisito de los tiempos, sino para maximizar la accesibilidad a la educación y la investigación patrimonial, cuestión clave para colaborar en la construcción de ese espacio de cooperación simétrica de los distintos agentes y de su patrimonio.

Así mismo, los continuos y acelerados cambios operados en los estudios patrimoniales sitúan a la investigación metodológica y a la innovación en procesos y estrategias en la frontera de los estudios patrimoniales. Si hay un componente envolvente en esta aproximación a la vanguardia de los estudios patrimoniales es la creatividad. Sin duda central en un campo en permanente transformación. La creatividad fundamenta el diseño de nuevos procesos particularizados para esos patrimonios emergentes; la creatividad se incorpora con fuerza en todos y cada uno de las fases del proceso. La cátedra CREhAR conecta así a través del patrimonio urbano las dos líneas de acción del programa de cultura de la Unesco: patrimonio y creatividad.

En nuestro abordaje, la creatividad no resulta opuesta al conocimiento racional; por el contrario, el auténtico conocimiento exige la integración de razón y emoción para entender nuestro entorno. El proyecto patrimonial constituye un proceso global, que implica tanto investigar y documentar como valorar, además de intervenir. Por tanto, la creatividad no es exclusiva de la faceta de intervención como puede inferirse de una interpretación limitada desde la acción de la arquitectura, sino que debe acompañar todo el proceso, desde la búsqueda e interpretación de las fuentes documentales, a la identificación de valores, la experiencia del lugar o su intervención.

La frontera del patrimonio continuamente se mueve, pero lo grande no debe entorpecer ver lo menudo, lo más frágil, lo más invisible y sin embargo aquello que más nos emociona.

\section{BIBLIOGRAFÍA}

- Consejo de Europa (2000) Convenio Europeo del Paisaje. Florencia. Disponible en: https://rm.coe.int/16802f3fbd [Consulta: 08/09/2021]

- European Commission (2004) SUIT: Sustainable development of Urban historical areas through an active Integration within Towns. Guidance for the Environmental Assessment of the impacts of certain plans, programmes or projects upon the heritage value of historical areas, in order to contribute to their long-term sustainability. Luxembourg: Office for Official Publications of the European Communities. Disponible en: https://op.europa.eu/es/publication-detail/-/ publication/c0fe3aca-1639-4554-aca7-d3dccdb2158d [Consulta: 08/09/2021]

- Oers, R. V. y Haraguchi, S. (ed.) (2003) Identification and documentation of modern heritage. Paris: UNESCO World Heritage Centre. Disponible en https://whc.unesco.org/ document/12 [Consulta: 08/09/2021]

- UNESCO (2021) Programas UNITWIN y de Cátedras UNESCO. Disponible en: https://es.unesco.org/programaunitwin-catedras [Consulta: 01/09/2021]

- UNESCO (2012) Recomendación sobre el paisaje urbano histórico, con inclusión de un glosario de definiciones. En Actas de la Conferencia General, 36 reunión, París, 25 de octubre - 10 de noviembre de 2011, v. 1: Resoluciones, p. 65. Disponible en http://maya.puec.unam.mx/planmanejoch/ Docum_Extern/06.pdf [Consulta: 08/09/2021]

- UNESCO (2000) Carta de CRACOVIA 2000. Principios para la Conservación y Restauración del Patrimonio Construido. Disponible en: https://www.iaph.es/export/sites/ default/galerias/documentacion_migracion/Documento_ PC/1267693158625_ph50-114.pdf [Consulta: 08/09/2021] 